\title{
Comparative Study on Efficacy of Various Types of Exposure Response Prevention Therapies on OCD
}

\author{
Mihir Ranjan Nayak ${ }^{1}$, Narendra nath Samantaray ${ }^{2 *}$, Preeti Singh ${ }^{3}$
}

\section{ABSTRACT}

Objective: The heterogeneity of OCD has various mixed findings related to the treatment procedures, psychological and pharmacological treatment. Consistent research has shown mixed findings regarding which form of ERP, ERP as Habituation tool or ERP as restructuring tool, is more efficacious. Hence this study is done to examine efficacies of various treatment procedures but importantly to propose a possible treatment choices based on efficacy and acceptability in Indian settings for OCD management. Method: Participants were adult outpatients $(\mathrm{N}=22)$ with primary OCD selected from OPD level and randomly assessed to two treatment groups; a) ERP(Habituation only) with SSRI b) ERP (ERP as restructuring tool) with SSRI. Participants received 12-14 exposure sessions, Result and Conclusions: ERP when used as a process of "habituation" is more efficacious in terms of treatment outcomes but when ERP used as both habituation and cognitive restructuring tool is more tolerable and acceptable by patients and also not prone to dropouts.

Keywords: Obsessive Compulsive Disorder, ERP, Behavior Therapy, Cognitive Therapy, CBT, SSRI, Y-BOCS

Obsessive Compulsive Disorder (OCD) is marked by three components (Mc Kay, 2004). One component, obsessions, has been defined as intrusive and unwanted thoughts, images or ideas, as well as doubts about actions. The second component, compulsions, has been defined as specific behavioral actions, including covert mental rituals, intended to neutralize the obsessions, or to verify behaviors that are the subject of doubts. In addition to these two primary components, individuals with the disorder engage in extensive avoidance to prevent the provocation of obsessions and their associated compulsions. And these avoidance and compulsions are maintaining factors of this disorder (Hawton, 1989). Interest in the treatment of obsessive-

\footnotetext{
${ }^{1}$ Associate Professor, Dept of Psychiatry, MHI, SCB Medical College, Cuttack, India

${ }^{2}$ Clinical Psychologist, Dept of Clinical Psychology, MHI, SCB Medical College, Cuttack, India

${ }^{3}$ Assistant Professor, Dept of Clinical Psychology, IMHH, Agra, India

*Responding Author
}

Received: December 30, 2016; Revision Received: January 20, 2017; Accepted: January 30, 2017

(C) 2017 Nayak M, Samantaray N, Singh P; licensee IJIP. This is an Open Access Research distributed under the terms of the Creative Commons Attribution License (www.creativecommons.org/licenses/by/2.0), which permits unrestricted use, distribution, and reproduction in any Medium, provided the original work is properly cited. 
compulsive disorder has increased with novel approaches to understanding and managing this often complex and debilitating disorder. Serotonin reuptake inhibitors (SRIs) (e.g., clomipramine and various selective serotonin reuptake inhibitors [SSRIs]) and cognitive and behavioural therapy involving exposure and ritual prevention have been found to be efficacious in randomized, controlled trials (APA, 2006).

In clinical practice, SRIs are used most frequently (Blanco, 2006), but because they typically yield only a 20\%-40\% reduction in OCD symptoms (Pigott, 1999), many SRI responders continue to have clinically significant symptoms. The heterogeneity of this disorder has various mixed findings related to the treatment procedures and choices hence this study is done not to only examine efficacies of various treatment procedures but importantly to propose a possible treatment hierarchy and choices based on efficacy and acceptability in Indian settings.

\section{Exposure and response prevention (ERP):}

For the past 35 years, the psychosocial treatment of choice has been exposure and response prevention. Treatment using this approach involves developing a hierarchy of presenting symptoms, from least fear producing to most, and then guiding the client through exposure to items on the hierarchy until the highest level items are readily tolerated at the same time response prevention is included, whereby the client is asked to refrain from completing the compulsions that would otherwise eliminate the anxiety or distressing emotional reaction (Rowa et al., 2007). Some data suggest that ERP is more effective if it includes not only habituation but also discussion of feared consequences and dysfunctional beliefs (Freeston, 1997). Over the past several decades, considerable research work has accumulated to show that ERP is an efficacious intervention for OCD (Foa \& Kozak, 1996). The method of delivery is important with in vivo therapist- assisted ERP, in conjunction with imagery, reported to produce the greatest change in symptom severity.

However, ERP is reported to be a difficult treatment to tolerate. Drop-out and refusal rates range 20\%-30\% (Stanley \& Turner, 1996), and many people leave with residual symptoms.

The concerns with classical ERP led to the development of alternate theories that would more directly address the changes that were thought to account for a decrease in the severity of OCD symptoms. It was consensually proposed that OCD patients attach a threatening meaning to the intrusions, whereas those without OCD appraise similar thoughts in a more neutral fashion (Carr;1974, Mc Fall 1979, Salkovskis, 1985). It is the appraisal that produces the emotional distress and the urge to neutralize the intrusive thought and these faulty appraisals are distributed in six domains: tendency to overestimate the risk and the responsibility; the importance and the power of thoughts and the need of controlling them; the need of certainty; and perfectionism (Salkovskis, 1985). 
A number of recent randomized controlled trials have investigated the efficacy of contemporary cognitive strategies in comparison to individual ERP (Cottraux et al., 2001; van Oppen et al., 1995) and group ERP (McLean et al., 2001) and with a subgroup of primary obsessionals (Freeston et al., 1997). These studies collectively reported that cognitively focused treatment is effective in significantly reducing the severity of obsessions and compulsions and that the treatment gains appear to be maintained through short-term follow- up. Although there were no significant differences between CBT and ERP, van Oppen (1995) reported trends in favor of CBT. Alternatively, McLean et al. (2001) reported that group ERP was marginally better than group CBT at post treatment and 3-month follow-up and that significantly more ERP participants had attained clinically significant improvement compared to CBT participants.

\section{Fluoxetine and Fluvoxamine (SSRI):}

Double-blind, placebo-controlled, and active-comparator studies indicate that fluoxetine and fluvoxamine is significantly more effective than placebo and equal in efficacy to clomipramine and certain SSRIs (citalopram, paroxetine). In addition, double-blind active-comparator studies suggest fluoxetine and fluvoxamine is comparable in efficacy to clomipramine and sertraline and superior in efficacy to phenelzine. Compared with clomipramine, both SSRI exhibited fewer side effects in many studies

\section{METHOD}

This study was conducted at Mental Health Institute (Centre of Excellence), SCB Medical College, Cuttack. Patients were selected at OPD level on the basis of their consent and inclusion criteria which are: a) Participants meeting ICD 10 criteria of OCD, b) Ages between 18-35 years old, and c) Participants having minimum education of matriculation. Exclusion criteria are; a) Participants having comorbid psychiatry diagnosis, b) Participants having predominantly obsessions type. Initially 26 participants (16 males and 10 females) were selected and were randomly assigned to the TWO TREATMENT GROUPS which are:

a) ERP(Habituation only) with SSRI

b) ERP (ERP as restructuring tool) with SSRI.

However, total number of four participants dropped out from the study (4 from group a).

\section{Treatment}

Following treatments versions are used:

1. Exposure and ritual prevention (Classical "Habituation" Version)

Two versions of ERP are used in the present study. For Category 1 (Group 1), the classical version of ERP is used as a part of Behaviour Therapy procedure where habituation is given emphasis where further discussion of feared consequences and dysfunctional beliefs related to ERP procedures (ERP as tool for cognitive restructuring) is not used. 


\section{Exposure and ritual prevention (As Cognitive Restructuring tool)}

But in second category, Group 2, the protocol for exposure and ritual prevention followed the procedures of Kozak and Foa (1997) which emphasized on both use of habituation and cognitive restructuring in ERP. Along with habituation further discussion of feared consequences and dysfunctional beliefs related to ERP procedures (ERP as tool for cognitive restructuring) are done.

Exposure exercises were arranged hierarchically, beginning with moderately distressing ones. It included 12-14 exposure sessions each. Both in vivo and imaginable exposures were conducted. Patients were encouraged to persist with each exposure until the distress decreased noticeably. As homework, patients were asked to record any rituals and spend at least 1 hour per day conducting self-guided exposures. To ensure this a family member of the participants are involved in one session where they were told the rationale, method and guidelines for practice sessions of ERP.

\section{SSRI (Fluoxetine and Fluvoxamine)}

In both group doses of fluoxetine for first month is 40-60mg per day and fluvoxamine $50 \mathrm{mg}$ per day and later homogeneously modified upon the subsequent consultation with psychiatrist.

\section{Assessments}

Independent evaluators, those who are not attached with this project, evaluated patients at baseline (week 0) and but after completion of treatments (after week 16). Symptom severity was evaluated using the Yale-Brown Obsessive Compulsive Scale (Goodman, 1989) for OCD.

\section{RESULTS}

Examination of Treatment Effects

Table -1:Y-BOCS Pre Post Test Scores

\begin{tabular}{|c|c|c|c|}
\hline Group & N & Mean & Std. Deviation \\
\hline Group1Pre & 11 & 28.4000 & 2.40832 \\
\hline Group1Post & 11 & 10.4000 & 2.07364 \\
\hline Group2Pre & 11 & 28.1429 & 2.03540 \\
\hline Group2Post & 11 & 13.0000 & .81650 \\
\hline
\end{tabular}

As mentioned in Table 1, the mean score of Y-BOCS on post test measures (graphically shown in Figure 1) on two treatment categories, are 10.4 and 13 respectively. In comparison to the pretest measures on these two categories of treatment combinations, 28.4 and 28.14, respectively, the post test measures of each treatment group suggest that participants in all groups made statistical and clinical gains following treatments. 
However, the result indicates Category 1(ERP as "Habituation" Version with SSRI) have the best treatment outcome post test scores followed by Category 2 (ERP as Restructuring Tool with SSRI), Category 2 (SSRI with CT) and Category 4 (SSRI alone) respectively.

\section{DISCUSSION AND IMPLICATIONS}

As described above, our results suggest, the mean score of Y-BOCS on post test measures on two treatment categories showed that all groups made statistical and clinically significant gains following treatment. However, it is important to place these findings in the context of what has been reported with EX/RP in other settings and with other samples. Comparing the percentage of reduction on the Y-BOCS observed here with those found across other EX/RP outcome studies that have used this outcome measure would be one alternative, yet these calculations do not take sample variances into account. Instead, we calculated within subject effect sizes based on the YBOCS for each of our treated groups, as recommended by Cohen (1988), and compared them with those derived from other recent EX/RP studies.

In the present study the effects of ERP (used as Habituation Tool) along with SSRI medications emerged as the best possible combination of treatment for OCD.

But the disadvantages in ERP when used as "Habituation tool" as noticed in present study bears synonymous with many other findings mentioned in literature. 4 participants dropped from Category 1 treatment group in between the ERP sessions and when asked reason he found subjectively difficult to resist ERP sessions along with other reasons. But in group 2 when ERP is used as cognitive restructuring no such incidence were there. And further it is not associated with any drop outs; it may be suggestible that ERP when used as element of cognitive restructuring might result in better adherence and tolerance than ERP only used as a method of "habituation". But those who completed yielded the best outcome in means.

But on the basis of the present study it can be said that ERP when used as CBT is more tolerable and acceptable to patients than ERP when used as "habituation" only. This finding that ERP when executed using as both principles is more acceptable to patients and may lessen the dropouts is a major implication of our research.

As mentioned above and in almost all literature that avoidance to triggering stimuli of OC symptoms are fuelling the disorder and is one of the basic maintain features of OC symptoms. In the absence of long-term outcome data, our findings cannot be used to help answer questions about whether patients who received combined treatment will later be able to withdraw from SSRI without experiencing a significant return of OCD symptoms.

To a certain extent, examination of the question of CBT treatment outcome with and without SSRI in a naturalistic study comes at the expense of internal validity. For example, we cannot 
determine the influence of patient choice (e.g., choosing CBT only over combined treatment) on treatment response. Nevertheless, it could well be said that our findings ought to be replicated with larger samples using more carefully controlled designs.

\section{CONCLUSIONS}

Major conclusions that can be derived from the present studies can be summed up in following ways: A) ERP (as “Habituation”), ERP (as Restructuring Tool), and SSRI all are effective treatment modules in OCD. B) The most efficacious treatment procedures in order of hierarchy are ERP (as Habituation) with SSRI. C) But when ERP used as a process of "habituation" is more efficacious in terms of treatment outcomes than any other and marginally superior version than other ERP procedures but D) when ERP used as cognitive restructuring tool is more tolerable and acceptable by patients and also not prone to dropouts as compared to ERP when used as habituation only, hence it is recommended to implement and use ERP as a common denominator to both BT and CT to patients. F) ERP is very highly and effectively decreases avoidance of fearful triggering stimuli in OCD patients.

\section{Acknowledgments}

The author appreciates all those who participated in the study and helped to facilitate the research process.

Conflict of Interests: The author declared no conflict of interests.

\section{REFERENCES}

Abramowitz, J. S. (1996). Variants of exposure and response prevention in the treatment of obsessive-compulsive disorder: A meta-analysis. Behavior therapy, 27(4), 583-600.

Abramowitz, J. S. (1997). Effectiveness of psychological and pharmacological treatments for obsessive-compulsive disorder: a quantitative review. Journal of consulting and clinical psychology, 65(1), 44.

Abramowitz, J. S. (1997). Effectiveness of psychological and pharmacological treatments for obsessive-compulsive disorder: a quantitative review. Journal of consulting and clinical psychology, 65(1), 44.

American Psychiatric Association. (2006). American Psychiatric Association Practice Guidelines for the treatment of psychiatric disorders: compendium 2006. American Psychiatric Pub.

Beck, J. S. (1979). Cognitive therapy. John Wiley \& Sons, Inc.

Blanco, C., Olfson, M., Stein, D. J., Simpson, H. B., Gameroff, M. J., \& Narrow, W. H. (2006). Treatment of obsessive-compulsive disorder by US psychiatrists. The Journal of clinical psychiatry, 67(6), 946-951.

Carr, A. T. (1974). Compulsive neurosis: a review of the literature. Psychological bulletin, 81(5), 311. 


\section{Comparative Study on Efficacy of Various Types of Exposure Response Prevention Therapies on OCD}

Christensen, H., Hadzi-Pavlovic, D., Andrews, G., \& Mattick, R. (1987). Behavior therapy and tricyclic medication in the treatment of obsessive-compulsive disorder: a quantitative review. Journal of Consulting and Clinical Psychology, 55(5), 701.

Cohen, J. (1988). Statistical power analysis: A computer program. Routledge.

Cottraux, J., Yao, S. N., Lafont, S., Mollard, E., Bouvard, M., Sauteraud, A., \& Dartigues, J. F. (2001). A randomized controlled trial of cognitive therapy versus intensive behavior therapy in obsessive compulsive disorder. Psychotherapy and Psychosomatics, 70(6), 288-297.

Cottraux, J., Yao, S. N., Lafont, S., Mollard, E., Bouvard, M., Sauteraud, A., \& Dartigues, J. F. (2001). A randomized controlled trial of cognitive therapy versus intensive behavior therapy in obsessive compulsive disorder. Psychotherapy and Psychosomatics, 70(6), 288-297.

Emmelkamp, P. M. G., Visser, S., \& Hoekstra, R. J. (1988). Cognitive therapy vs exposure in vivo in the treatment of obsessive-compulsives. Cognitive Therapy and Research, 12(1), 103-114.

Emmelkamp, P. M., \& Beens, H. (1991). Cognitive therapy with obsessive-compulsive disorder: A comparative evaluation. Behaviour Research and Therapy, 29(3), 293-300.

Fals-Stewart, W., Marks, A. P., \& Schafer, J. (1993). A comparison of behavioral group therapy and individual behavior therapy in treating obsessive-compulsive disorder. The Journal of nervous and mental disease, 181(3), 189-193.

Foa, E. B., \& Kozak, M. J. (1986). Emotional processing of fear: exposure to corrective information. Psychological bulletin, 99(1), 20.

Foa, E. B., Liebowitz, M. R., Kozak, M. J., Davies, S., Campeas, R., Franklin, M. E., ... \& Simpson, H. B. (2007). Randomized, placebo-controlled trial of exposure and ritual prevention, clomipramine, and their combination in the treatment of obsessivecompulsive disorder.

Franklin, M. E., Abramowitz, J. S., Bux Jr, D. A., Zoellner, L. A., \& Feeny, N. C. (2002). Cognitive-behavioral therapy with and without medication in the treatment of obsessivecompulsive disorder. Professional Psychology: Research and Practice, 33(2), 162.

Freeston, M. H., Ladouceur, R., Gagnon, F., Thibodeau, N., Rhéaume, J., Letarte, H., \& Bujold, A. (1997). Cognitive-behavioral treatment of obsessive thoughts: A controlled study. Journal of Consulting and Clinical Psychology, 65(3), 405.

Freeston, M. H., Ladouceur, R., Gagnon, F., Thibodeau, N., Rhéaume, J., Letarte, H., \& Bujold, A. (1997). Cognitive-behavioral treatment of obsessive thoughts: A controlled study. Journal of Consulting and Clinical Psychology, 65(3), 405.

Freeston, M. H., Ladouceur, R., Gagnon, F., Thibodeau, N., Rhéaume, J., Letarte, H., \& Bujold, A. (1997). Cognitive-behavioral treatment of obsessive thoughts: A controlled study. Journal of Consulting and Clinical Psychology, 65(3), 405. 
Goodman, W. K., Price, L. H., Rasmussen, S. A., Mazure, C., Fleischmann, R. L., Hill, C. L., ... \& Charney, D. S. (1989). The Yale-Brown obsessive compulsive scale: I. Development, use, and reliability. Archives of general psychiatry, 46(11), 1006-1011.

Hawton, K. E., Salkovskis, P. M., Kirk, J. E., \& Clark, D. M. (1989). Cognitive behaviour therapy for psychiatric problems: a practical guide. Oxford University Press.

Kozak, M. J., \& Foa, E. B. (1994). Obsessions, overvalued ideas, and delusions in obsessivecompulsive disorder. Behaviour Research and Therapy, 32(3), 343-353.

Kozak, M. J., \& Foa, E. B. (1997). Mastery of obsessive-compulsive disorder: A cognitivebehavioral approach. Psychological Corporation.

Lindsay, M., Crino, R., \& Andrews, G. (1997). Controlled trial of exposure and response prevention in obsessive-compulsive disorder. The British Journal of Psychiatry, 171(2), 135-139.

Markarian, Y., Larson, M. J., Aldea, M. A., Baldwin, S. A., Good, D., Berkeljon, A., ... \& McKay, D. (2010). Multiple pathways to functional impairment in obsessive-compulsive disorder. Clinical psychology review, 30(1), 78-88.

Marks, I., \& O'Sullivan, G. (1988). Drugs and psychological treatments for agoraphobia/panic and obsessive-compulsive disorders: a review. The British Journal of Psychiatry, 153(5), 650-658.

Mawson, D., Marks, I. M., \& Ramm, L. (1982). Clomipramine and exposure for chronic obsessive-compulsive rituals: III. Two year follow-up and further findings. The British Journal of Psychiatry, 140(1), 11-18.

McFall, M. E., \& Wollersheim, J. P. (1979). Obsessive-compulsive neurosis: A cognitivebehavioral formulation and approach to treatment. Cognitive Therapy and Research, 3(4), 333-348.

McKay, D., Abramowitz, J. S., Calamari, J. E., Kyrios, M., Radomsky, A., Sookman, D., ... \& Wilhelm, S. (2004). A critical evaluation of obsessive-compulsive disorder subtypes: symptoms versus mechanisms. Clinical psychology review, 24(3), 283-313.

McLean, P. D., Whittal, M. L., Thordarson, D. S., Taylor, S., Söchting, I., Koch, W. J., ... \& Anderson, K. W. (2001). Cognitive versus behavior therapy in the group treatment of Obsessive-Compulsive disorder. Journal of Consulting and Clinical Psychology, 69(2), 205.

Pigott, T. A., \& Seay, S. M. (1999). A review of the efficacy of selective serotonin reuptake inhibitors in obsessive-compulsive disorder. Journal of Clinical Psychiatry.

Rachman, S. A. (1997). Cognitive theory of obsessions. Behaiour Research Theory, 35(9):793802.

Rowa, K., Antony, M. M., Summerfeldt, L. J., Purdon, C., Young, L., \& Swinson, R. P. (2007). Office-based vs. home-based behavioral treatment for obsessive-compulsive disorder: A preliminary study. Behaviour Research and Therapy, 45(8), 1883-1892.

Salkovskis, P. M. (1985). Obsessional-compulsive problems: A cognitive-behavioural analysis. Behaviour research and therapy, 23(5), 571-583. 
Salkovskis, P. M. (1985). Obsessional-compulsive problems: A cognitive-behavioural analysis. Behaviour research and therapy, 23(5), 571-583.

Salkovskis, P. M. (1989). Cognitive-behavioural factors and the persistence of intrusive thoughts in obsessional problems. Behaviour research and therapy, 27(6), 677-682.

Salkovskis, P. M., Forrester, E., \& Richards, C. (1997). Cognitive-behavioural approach to understanding obsessional thinking. The British journal of psychiatry. Supplement, (35), 53-63.

Stanley, M. A., \& Turner, S. M. (1996). Current status of pharmacological and behavioral treatment of obsessive-compulsive disorder. Behavior therapy, 26(1), 163-186.

Van Balkom, A. J., van Oppen, P., Vermeulen, A. W., van Dyck, R., Nauta, M. C., \& Vorst, H. C. (1994). A meta-analysis on the treatment of obsessive compulsive disorder: a comparison of antidepressants, behavior, and cognitive therapy. Clinical Psychology Review, 14(5), 359-381.

Van Oppen, P., De Haan, E., Van Balkom, A. J., Spinhoven, P., Hoogduin, K., \& Van Dyck, R. (1995). Cognitive therapy and exposure in vivo in the treatment of obsessive compulsive disorder. Behaviour research and therapy, 33(4), 379-390.

Van Oppen, P., De Haan, E., Van Balkom, A. J., Spinhoven, P., Hoogduin, K., \& Van Dyck, R. (1995). Cognitive therapy and exposure in vivo in the treatment of obsessive compulsive disorder. Behaviour research and therapy, 33(4), 379-390.

Warren, R., \& Thomas, J. C. (2001). Cognitive-behavior therapy of obsessive-compulsive disorder in private practice: An effectiveness study. Journal of Anxiety Disorders, 15(4), 277-285.

Whittal, M. L., Thordarson, D. S., \& McLean, P. D. (2005). Treatment of obsessive-compulsive disorder: Cognitive behavior therapy vs. exposure and response prevention. Behaviour Research and Therapy, 43(12), 1559-1576.

How to cite this article: Nayak M, Samantaray N, Singh P (2017), Comparative Study on Efficacy of Various Types of Exposure Response Prevention Therapies on OCD, International Journal of Indian Psychology, Volume 4, Issue 2, No. 86, ISSN:2348-5396 (e), ISSN:2349-3429 (p), DIP:18.01.039/20170402, ISBN:978-1-365-68609-2 